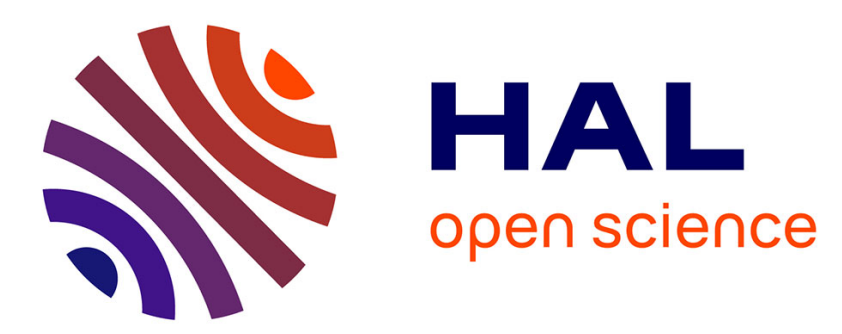

\title{
A kinetic isotope effect during ice formation by water freezing
}

R. Souchez, J. Jouzel, R. Lorrain, S. Sleewaegen, M. Stiévenard, V. Verbeke

\section{To cite this version:}

R. Souchez, J. Jouzel, R. Lorrain, S. Sleewaegen, M. Stiévenard, et al.. A kinetic isotope effect during ice formation by water freezing. Geophysical Research Letters, 2000, 27 (13), pp.1923-1926. 10.1029/2000GL006103 . hal-03110173

\section{HAL Id: hal-03110173 \\ https://hal.science/hal-03110173}

Submitted on 24 Jan 2021

HAL is a multi-disciplinary open access archive for the deposit and dissemination of scientific research documents, whether they are published or not. The documents may come from teaching and research institutions in France or abroad, or from public or private research centers.
L'archive ouverte pluridisciplinaire HAL, est destinée au dépôt et à la diffusion de documents scientifiques de niveau recherche, publiés ou non, émanant des établissements d'enseignement et de recherche français ou étrangers, des laboratoires publics ou privés. 


\title{
A kinetic isotope effect during ice formation by water freezing
}

\author{
R. Souchez, ${ }^{1}$ J. Jouzel, ${ }^{2}$ R. Lorrain, ${ }^{1}$ S. Sleewaegen, ${ }^{1}$ M. Stiévenard ${ }^{2}$ and V. Verbeke ${ }^{1}$
}

\begin{abstract}
A kinetic isotope effect is known to occur during ice formation from water vapour in a cloud ; it is due to the difference in molecular diffusivities in air of $\mathrm{HDO}$ and $\mathrm{H}_{2}{ }^{18} \mathrm{O}$ molecules. A similar effect is likely during water freezing since diffusion coefficients of $\mathrm{HDO}$ and $\mathrm{H}_{2}{ }^{18} \mathrm{O}$ are also different in liquid water. Their values are however less different from each other than those in air. Therefore, such a kinetic isotope effect during water freezing is less frequently observed in Nature. This paper describes a situation in Antarctica where this effect is conspicuous in icings (aufeis). In this type of ice indeed there is no relationship between $\delta \mathrm{D}$ (or $\delta^{18} \mathrm{O}$ ) and deuterium excess whereas a clear inverse relationship between these parameters exists in ice formed by water freezing when equilibrium isotopic fractionation applies. This kinetic effect is potentially present in hail within clouds, in infiltration ice (formed during sea ice growth) and in some kinds of ground ice.
\end{abstract}

\section{The Glaciological Context}

In some areas of North Victoria Land, Antarctica, flowing water can sometimes be observed during the summer even if air temperature is lower than the freezing point (as indicated by automatic weather stations). This situation occurs in places swept across by strong katabatic winds which are responsible for snow-free rock outcrops and relatively strong ice sublimation. Absorption of solar radiation by rock can lead to liquid meltwater production from the small remaining snow patches.

One such area (Fig. 1) is the confluence of Priestley and Corner Glaciers (lat. $74^{\circ} 30^{\prime} \mathrm{S}$; long. $163^{\circ} 30^{\prime} \mathrm{E}$ ). A rock outcrop called Black Ridge - the name was given since it is mainly snow-free - is at the origin of flowing water during some summer days. This water reaches a nearby frozen lake and freezes on its surface. Successive events of this kind are responsible for successive ice layers so that an icing is formed. Two icings in this area have been sampled for isotopic analyses. The analyses have been performed at the Centre d'Etudes Nucléaires de Saclay with an accuracy of $0.5 \% \circ$ in $\delta \mathrm{D}$ and $0.1 \% \circ$ in $\delta^{18} \mathrm{O}$. The $\delta$-values are expressed in per mil versus V-SMOW.

\section{Isotopic Fractionation by Water Freezing}

Freezing of water involves isotopic fractionation because the different kinds of water molecules freeze at slightly different temperatures. In a $\delta D-\delta^{18} \mathrm{O}$ diagram, ice samples resulting from water freezing are aligned on a straight line with a slope - called

\footnotetext{
'Département des Sciences de la Terre, Université de Bruxelles, Brussels, Belgium.

${ }^{2}$ Laboratoire des Sciences du Climat et de l'Environnement - CEA Saclay, France.
}

Copyright 2000 by the American Geophysical Union.

Paper number 2000 GL006103. 0094-8276/00/2000GL006103\$05.00 freezing slope - different from that of the Meteoric Water Line $\left(\delta D=8 \delta^{18} \mathrm{O}+\mathrm{d}\right)$. This freezing slope is observed in a closed system and also in an open system if the water input has the same isotopic composition than initial water [Jouzel and Souchez, 1982; Souchez and Jouzel, 1984].

The freezing slope $S$ is given by the following equation in open systems :

$$
S=\frac{\alpha_{D}}{\alpha_{18} \mathrm{O}}\left(\frac{\alpha_{D}-1}{\alpha_{18} \mathrm{O}^{-1}}\right)\left(\frac{1000+\delta_{\mathrm{i}} \mathrm{D}}{1000+\delta_{\mathrm{i}}{ }^{18} \mathrm{O}}\right)
$$

where $\delta_{1} \mathrm{D}$ and $\delta_{1}{ }_{18} \mathrm{O}$ are the respective $\delta$-values in deuterium and oxygen 18 of the initial water and $\alpha_{D}, \alpha_{18_{0}}$ the respective equilibrium fractionation coefficients for deuterium and oxygen 18. Equation (1) shows that the freezing slope is lower when the initial water has more negative $\delta$-values. Anyway, the freezing slope is always lower than the slope of the Meteoric Water Line (MWL) which is about eight.

Modelling of the redistribution of isotopic species during water freezing is mathematically equivalent to modelling of the
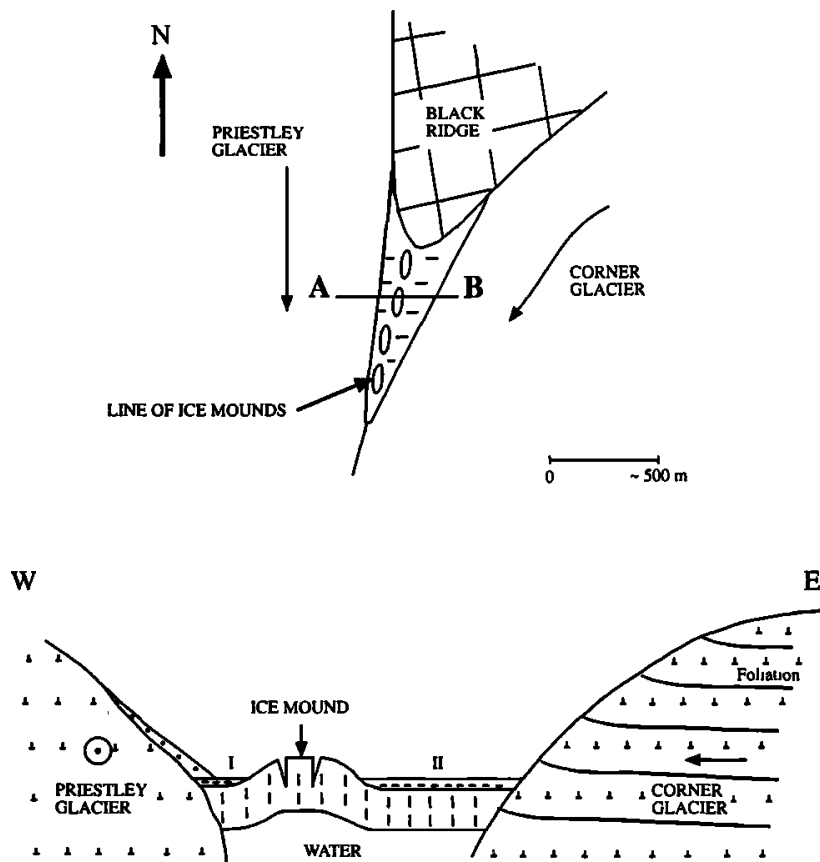

$\mathbf{A}$

B

icing with successive ice layers $(0,5-1 \mathrm{~cm}$ in length)

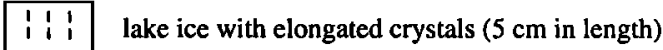

+ 1 glacier bubbly ice with equigranular crystals ( $1 \mathrm{~cm}$ diameter)

... superimposed ice with very small ice crystals $(0,2-0,3 \mathrm{~cm}$ diameter $)$

Figure 1. Icings at the confluence of Priestley and Corner Glaciers. I and II are the locations where the icings were sampled. 

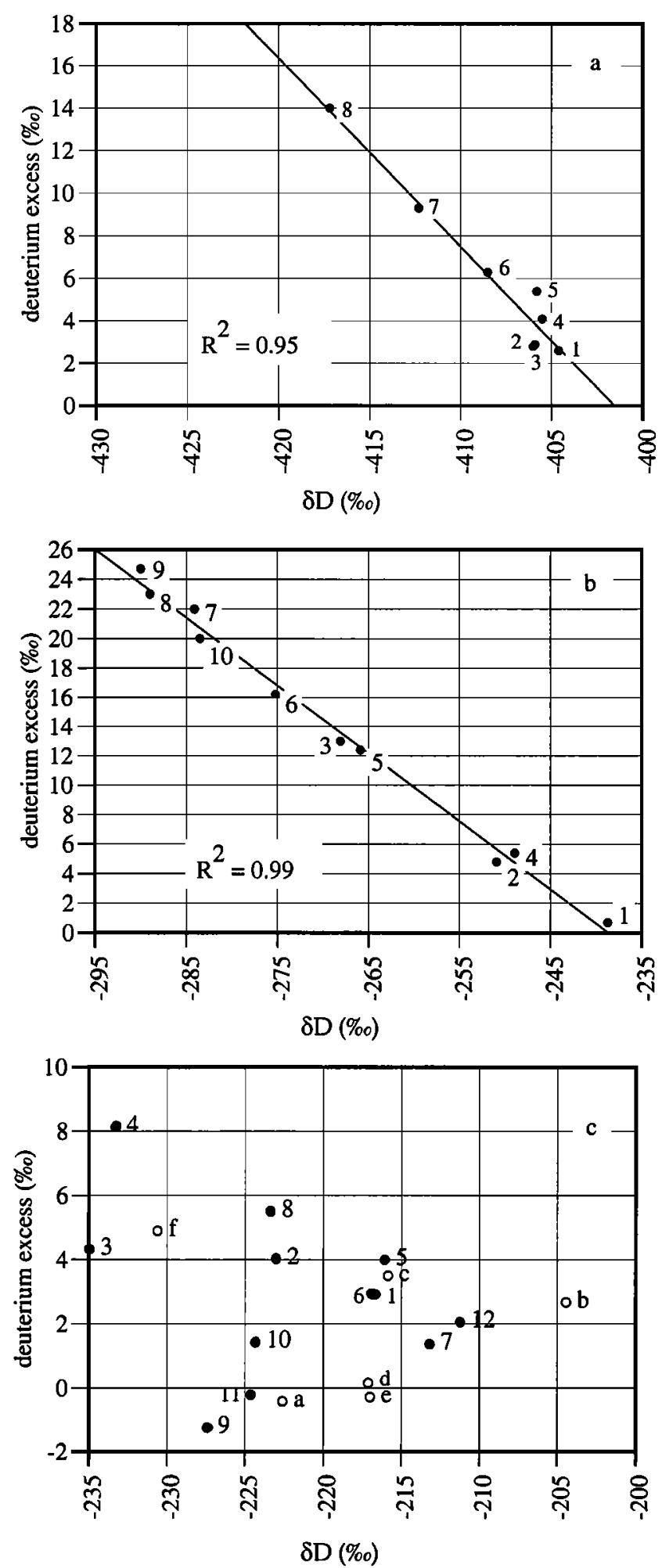

Figure 2. $\delta \mathrm{D}-\mathrm{d}$ relationships in ice samples from an Antarctic meltwater freezing experiment (a), lake ice samples from a small Antarctic lake situated in the Dry Valleys area (b), and icing samples from the Black Ridge area, North Victoria Land (c). Numbers are increasing with depth. In $2 c$, letters from a to f refer to icing I and numbers from 1 to 12 refer to icing II.

redistribution of a solute during solidification, a problem extensively studied for preparation of materials by zone melting [Tiller et al., 1953]. The distribution of heavy isotope species in ice during water freezing is related to their distribution in the liquid immediately adjacent to the freezing front. Since isotopic diffusion in ice is slow (diffusion coefficient $\approx 10^{-11} \mathrm{~cm}^{2} \mathrm{~s}^{-1}$ ), the distribution of deuterium and oxygen 18 in the ice can be deduced from knowledge of their variations in the liquid at the interface during freezing. In a $\delta \mathrm{D}-\delta^{18} \mathrm{O}$ diagram, the position of an ice sample on the freezing slope is dependent in the case of an open reservoir on the freezing rate $v$ and on the thickness $h$ of the boundary layer close to the interface where isotope transport in water is solely due to diffusion [Souchez et al., 1987]. The relationship between isotopic composition of the ice, freezing rate and boundary layer thickness can be very well approximated for open systems by an equation similar to Burton's equation [Burton et al., 1953] :

$$
\left(\frac{1000+\delta_{\mathrm{s}}}{1000+\delta_{\mathrm{i}}}\right)=\frac{\alpha}{\alpha-(\alpha-1) \mathrm{e}^{\frac{-h . v}{\mathrm{D}}}}
$$

where $\delta_{\mathrm{s}}$ and $\delta_{\mathrm{t}}$ are the respective $\delta$-values of the ice and of the initial water, $\alpha$ the appropriated equilibrium fractionation coefficient and $D$ the appropriated diffusion coefficient. This equation can be solved either for deuterium or oxygen 18 .

Independently, if the rate of water supply is less than the freezing rate, the position of an ice sample on the freezing slope is also dependent on the percentage of freezing [Jouzel and Souchez, 1982]. A progressive impoverishment of the heavy isotopes occurs in both the residual water and the ice layers in the course of freezing.

Since the freezing slope has a value lower than eight, an inverse linear relationship between the deuterium excess $\left(d=\delta D-8 \delta^{18} O\right)$ of ice samples resulting from water freezing and $\delta$-values of the same samples is expected. Variations in deuterium excess are in this case the result of the conditions prevailing during freezing (freezing rate, boundary layer thickness, percentage of freezing of the reservoir). This is in strong contrast with the general acceptation of this concept in precipitation where it is mainly dependent on the temperature and the relative humidity of the air in the source area [Jouzel et al., 1982; Merlivat and Jouzel, 1979].

\section{Evidence for a Kinetic Isotope Effect}

Six ice samples were analysed for $\delta D$ and $\delta^{18} \mathrm{O}$ along the $3.5 \mathrm{~cm}$ vertical profile of icing I and twelve ice samples along the $5 \mathrm{~cm}$ vertical profile of icing II (Fig. 1). Results of these analyses are compared to analyses of ice samples from a freezing experiment and from an ice core from a small Antarctic lake situated in the Dry Valleys area. Eight ice samples are distributed over a total ice thickness of $10 \mathrm{~cm}$ in the experiment. Ten ice samples were taken from the $3.3 \mathrm{~m}$ lake ice core. Despite a difference in resolution, large ranges in $\delta$-values exist in the different situations, making the comparison valid.

Figure 2 gives the $\delta \mathrm{D}-\mathrm{d}$ relationships in :

a) samples of ice resulting from a water freezing experiment [Souchez and Jouzel, 1984] with Antarctic ice meltwater having initial isotopic composition $\delta \mathrm{D}=-408.8 \%$ o, $\delta^{18} \mathrm{O}=-51.7 \%$ o (Fig. 2.a),

b) samples of lake ice from a small lake frozen to the bottom, adjacent to Suess Glacier in Taylor Valley, South Victoria Land (Fig. 2.b) and

c) samples of ice from icings in the Black Ridge area (Fig. 2.c).

In the first two situations, a very good inverse linear relationship is displayed on a $\delta \mathrm{D}-\mathrm{d}$ diagram. This is the consequence of the alignment of sample points along a freezing slope. There is indeed a very good correspondence between the calculated freezing slope from equation (1) and the slope of the best fit line displayed on a $\delta \mathrm{D}-\delta^{18} \mathrm{O}$ diagram. Respective values 


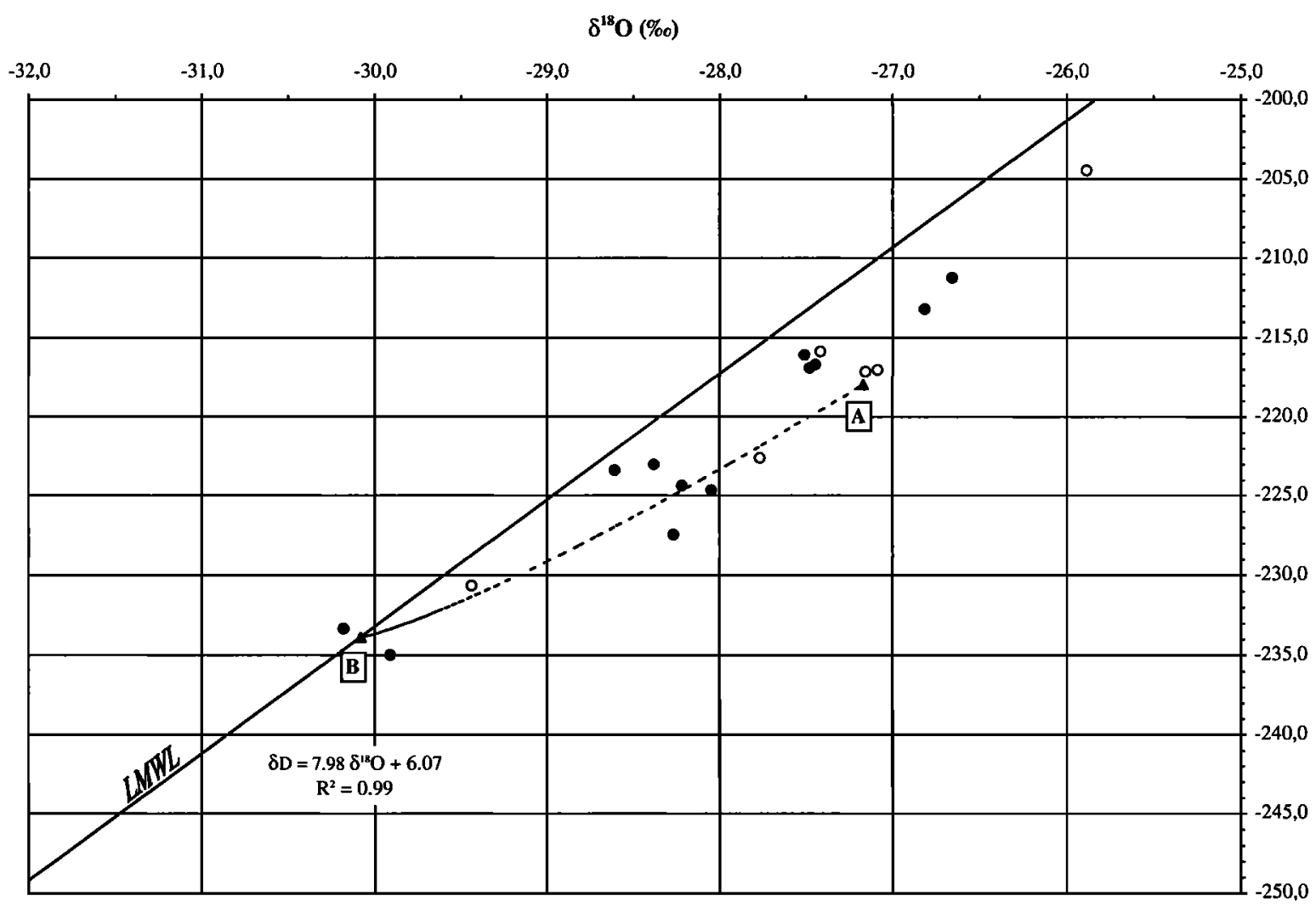

Figure 3. $\delta \mathrm{D}-\delta^{18} \mathrm{O}$ diagram for the icing samples from the Black Ridge area. Solid line : Local Meteoric Water Line (LMWL) ; dotted line : Burton's equation.

are 4.32 and 4.37 for the experiment ; 5.44 and 5.47 for lake ice from the Taylor Valley lake. For the latter case, the $\delta$-values of the intersection point between the local MWL and the regression line are taken as those of the initial water. In these two situations, the $\delta$-values generally decrease towards the base of the ice cover, suggesting the progressive downward movement of a freezing front. The nearly closed system formed is responsible for the impoverishment of heavy isotopes as the volume of the remaining liquid decreases.

By contrast, there is no such a linear relationship in a $\delta \mathrm{D}-\mathrm{d}$ diagram for the icing from the Black Ridge area (Fig. 2.c). The absence of correlation and the fact that no trend is displayed in the distribution of heavy isotopes with depth in the ice cover imply :

a) non-existence of a freezing slope,

b) freezing of successive thin water layers in an open system so that equation (2) could apply.

Figure 3 shows the local MWL in the Black Ridge area determined by thirty one samples of local snow, superimposed ice and glacier ice. Also displayed in the figure are the points representing the icing samples. Except one, all of them are located below the MWL. Those with the most negative $\delta$ values are very close to this line. The whole set of points shows a slight upward (concave up) curvature. As developed below, this is the consequence of a kinetic isotope effect.

The respective values for deuterium and oxygen 18 of the diffusion coefficients in water at $0{ }^{\circ} \mathrm{C}$ are $1.110^{-5} \mathrm{~cm}^{2} \mathrm{~s}^{-1}$ and $1.3310^{-5} \mathrm{~cm}^{2} \mathrm{~s}^{-1}$ [Wang et al., 1953]. Using equation (2) with these values the curved dotted line of figure 3 is obtained. The isotopic composition of initial water considered in equation (2) is taken as $\delta \mathrm{D}=-233.9 \%$ and $\delta^{18} \mathrm{O}=-30.1 \%$. These values would correspond to the meltwater of a snow or ice sample displayed on the MWL of figure 3 as point $B$ which is the closest point to the most negative icing samples. Position of a point on the dotted curve is dependent on the freezing rate $v$ and / or the boundary layer thickness $h$. This curved line is theoretically developed between point $A$ representing the maximum enrichment in heavy isotopes on the freezing slope taking into account the equilibrium fractionation coefficients and point $B$ representing the initial water. For a given value of $h$, the point representing an ice sample is closer to the one representing the initial water if $v$ is higher. For a given value of $v$, it is closer if $h$ is greater. There is however no possible way to determine both $v$ and $h$ at a given situation. This is only possible in sea ice, for which a second equation combining $\mathrm{v}$ and $\mathrm{h}$ can be derived for salinity [Eicken, 1998; Souchez et al., 1988]. If the two diffusion coefficients for $\mathrm{HDO}$ and $\mathrm{H}_{2}{ }^{18} \mathrm{O}$ in water were identical, equation (2) solved for deuterium and oxygen 18 would lead to a straight line between $A$ and $B$ in figure 3 , this straight line being the freezing slope.

On figure 3, a relatively good match exists between the distribution of icing samples and the curve given by Burton's equation. Some icing samples have however less negative $\delta$-values than those of point A. Therefore, the use of equation (2) with a single initial water is not sufficient for explaining the isotopic composition of the icings. Since there is no fractionation on ice melting [Moser and Stichler, 1980], the various snow and ice samples on the MWL could produce initial waters with different isotopic compositions. A bundle of curves as defined in equation (2) which are parallel shifted along the local MWL is required to fully understand the isotopic composition of the icings. 


\section{Conclusion}

Due to a difference in molecular diffusivities in air of HDO and $\mathrm{H}_{2}{ }^{18} \mathrm{O}$, a kinetic isotope effect exists in a cold or mixed cloud [Jouzel and Merlivat, 1984].

A similar kinetic isotope effect is found to be present during the formation of icings in Antarctica. Such an effect has however not occurred during the formation of the lake ice from the Taylor Valley lake. The difference in behaviour is recorded in the $\delta \mathrm{D}-\mathrm{d}$ relationship.

Since diffusion coefficients of $\mathrm{HDO}$ and $\mathrm{H}_{2}{ }^{18} \mathrm{O}$ molecules in $\mathrm{H}_{2}{ }^{16} \mathrm{O}$ water are different from each other by only $17 \%$, special conditions are required for such a kinetic effect to take place. Freezing rate is probably the most important governing factor. Icing due to rapid freezing of meltwater produced under favourable local conditions at subfreezing air temperatures is the most likely type of ice where such an effect can be recorded. Most icings in Antarctica, because of rapid freezing, have probably this specific isotopic signature. Further implications of this study are possible for other natural phenomena such as formation of hail in convective clouds, formation of infiltration ice during sea ice growth and ground ice development in the active layer of permafrost.

Acknowledgements. The "Programma Nazionale di Richerche in Antardide" (PNRA) is gratefully acknowledged for having supported the field work of the first author in Terra Nova Bay in 1989-90. Thanks are also due to Antarctica New Zealand for having supported the field trip of the third author in the Dry Valleys area in 1997-98. This paper is a contribution to the Belgian Antarctic Program (Science Policy Office).

\section{References}

Burton, J.A., R.C. Prim, and W.P. Slichter, The distribution of solute in crystal growth from the melt. Part I : Theoretical, J. of Chemical Physics, 21 (1), 1987-1991, 1953.

Eicken, H., Deriving modes and rates of ice growth in the Weddell Sea from microstructural, salinity and stable-isotope data, in Antarctic sea ice : physical processes, interactions and variability, edited by M.O. Jeffries, pp. 89-122, American Geophysical Union, Washington, D.C., 1998.
Jouzel, J., L. Merlivat, and C. Lorius, Deuterium excess in an East Antartic ice core suggests higher relative humidity at the oceanic surface during the last glacial maximum, Nature, 299 (5885), 688-691, 1982.

Jouzel, J., and R. Souchez, Melting-refreezing at the glacier sole and the isotopic composition of the ice, J. Glaciol., 28 (98), 35-42, 1982.

Jouzel, J., and L. Merlivat, Deuterium and oxygen 18 in precipitation: modeling of the isotopic effects during snow formation, J. of Geophys. Res., 89 (D7), 11749-11757, 1984.

Merlivat, L., and J. Jouzel, Global climatic interpretation of the deuterium-oxygen-18 relationship for precipitation, $J$. of Geophys. Res., 84 (C8), 5029-5033, 1979.

Moser, H., and W. Stichler, Environmental isotopes in ice and snow, in Handbook of Environmental Isotope Geochemistry, the terrestrial environment, $1 A$, edited by P. Fritz, and J. Fontes, pp. 141-178, Elsevier, New York, 1980.

Souchez, R., and J. Jouzel, On the isotopic composition in $\delta \mathrm{D}$ and $\delta^{18} \mathrm{O}$ of water and ice during freezing, Journal of Glaciology, 30 (106), 369$372,1984$.

Souchez, R., J.-L. Tison, and J. Jouzel, Freezing rate determination by the isotopic composition of the ice, Geophysical Research Letters, 14 (6), 599-602, 1987.

Souchez, R., J.-L. Tison, and J. Jouzel, Deuterium concentration and growth rate of Antarctic first-year sea ice, Geophysical Research Letters, 15 (12), 1385-1388, 1988.

Tiller, W.A., K.A. Jackson, J.W. Rutter, and B. Chalmers, The redistribution of solute atoms during the solidification of metals, Acta Metallurgica, 1, 428-437, 1953.

Wang, J., C. Robinson, and I. Edelman, Self-diffusion and structure of liquid water. III. Measurement of the self-diffusion of liquid water with $\mathrm{H} 2, \mathrm{H} 3$ and $\mathrm{O} 18$ as tracers, $J$. of the American Chemical Society, $75,466-470,1953$.

R. Lorrain, S. Sleewaegen, R. Souchez and V. Verbeke, Département des Sciences de la Terre et de l'Environnement, Faculté des Sciences, CP 160/03, avenue F.D. Roosevelt 50, B-1050 Bruxelles, Belgium (e-mail : glaciol@ulb.ac.be)

J. Jouzel and M. Stievenard, Laboratoire des Sciences du Climat et de l'Environnement, UMR CEA-CNRS 1572, CEA Saclay, Orme des Mérisiers, F-91191 Gif sur Yvette, France (e-mail : jouzel, misti@1sce.saclay.cea.fr)

(Received December 16, 1999; revised March 29, 2000; accepted May 9, 2000.) 